
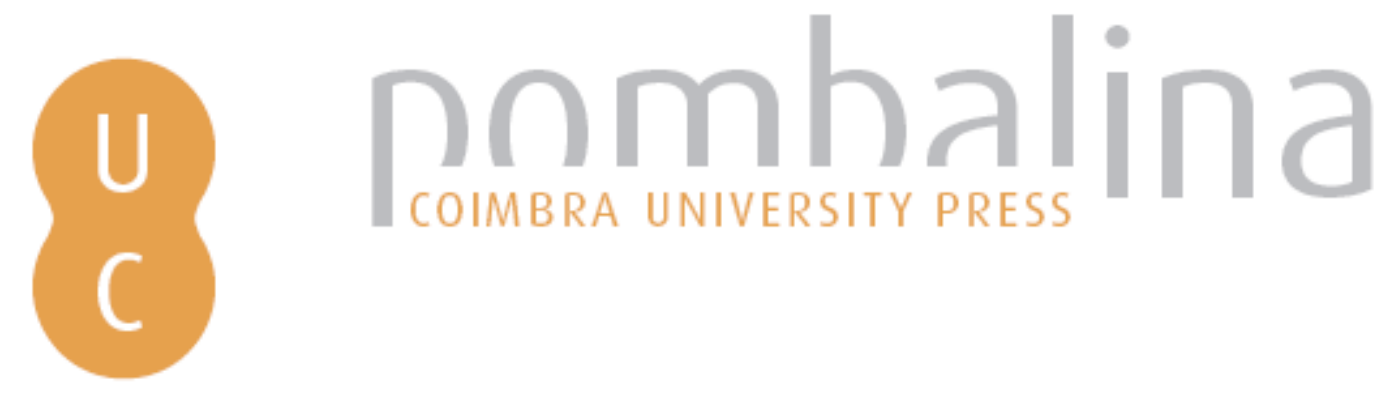

\title{
Sistemas de aviso meteorológico - estudo comparativo de avisos emitidos, condições meteorológicas registadas e registo de ocorrências
}
Autor(es):
Gomes, Ricardo; Ferreira, Válter; Brites, Rafael
Publicado por: $\begin{aligned} & \text { Imprensa da Universidade de Coimbra; RISCOS - Associação } \\ & \text { Portuguesa de Riscos, Prevenção e Segurança }\end{aligned}$
URL persistente:
URI:http://hdl.handle.net/10316.2/34854
DOI:
DOI:http://dx.doi.org/10.14195/978-989-96253-3-4_56
Accessed : $\quad$ 26-Apr-2023 01:51:46

A navegação consulta e descarregamento dos títulos inseridos nas Bibliotecas Digitais UC Digitalis, UC Pombalina e UC Impactum, pressupõem a aceitação plena e sem reservas dos Termos e Condições de Uso destas Bibliotecas Digitais, disponíveis em https://digitalis.uc.pt/pt-pt/termos.

Conforme exposto nos referidos Termos e Condições de Uso, o descarregamento de títulos de acesso restrito requer uma licença válida de autorização devendo o utilizador aceder ao(s) documento(s) a partir de um endereço de IP da instituição detentora da supramencionada licença.

Ao utilizador é apenas permitido o descarregamento para uso pessoal, pelo que o emprego do(s) título(s) descarregado(s) para outro fim, designadamente comercial, carece de autorização do respetivo autor ou editor da obra.

Na medida em que todas as obras da UC Digitalis se encontram protegidas pelo Código do Direito de Autor e Direitos Conexos e demais legislação aplicável, toda a cópia, parcial ou total, deste documento, nos casos em que é legalmente admitida, deverá conter ou fazer-se acompanhar por este aviso.

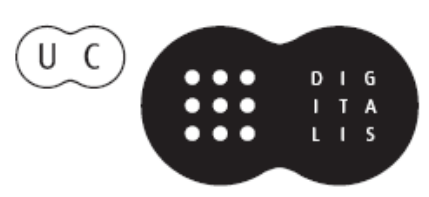



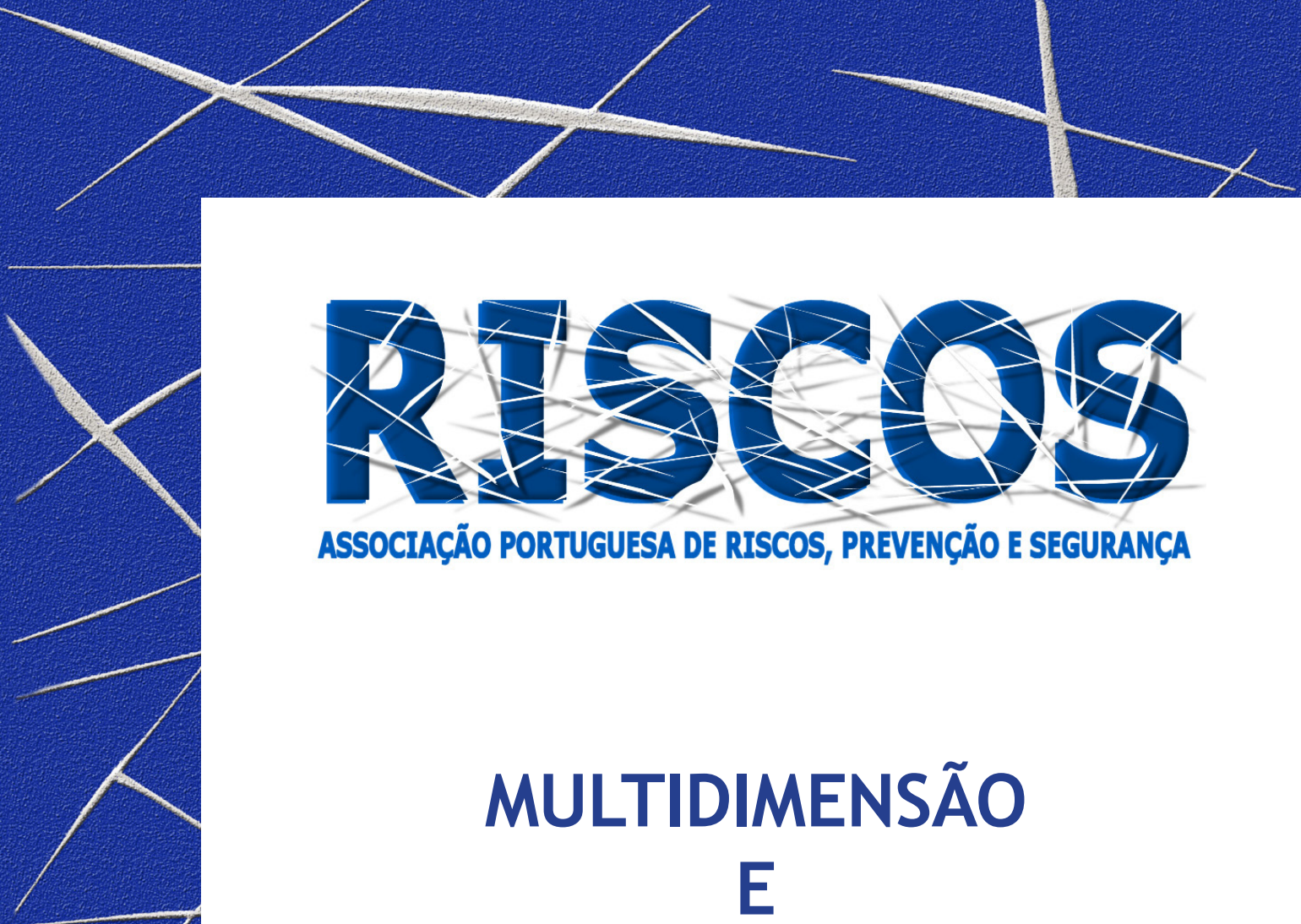

ASSOCIAÇÃO PORTUGUESA DE RISCOS, PREVENCCÃO E SEGURANÇA

MULTIDIMENSÃO

E
TERRITÓRIOS DE RISCO

III Congresso Internacional

I Simpósio Ibero-Americano

VIII Encontro Nacional de Riscos

Guimarães

2014 


\title{
SISTEMAS DE AVISO METEOROLÓGICO - ESTUDO COMPARATIVO DE AVISOS EMITIDOS, CONDIÇÕES METEOROLÓGICAS REGISTADAS E REGISTO DE OCORRÊNCIAS
}

\author{
Ricardo Gomes \\ Serviço Regional de Proteção Civil, IP-RAM \\ ricardo.gomes@procivmadeira.pt \\ Válter Ferreira \\ Serviço Regional de Proteção Civil, IP-RAM \\ valter.ferreira@procivmadeira.pt \\ Rafael Brites \\ Serviço Regional de Proteção Civil, IP-RAM \\ rafael.brites@procivmadeira.pt
}

\begin{abstract}
RESUMO
O Sistema de Avisos Meteorológicos (SAM) assegurado pelo Instituto Português do Mar e da Atmosfera procede ao aviso da população em geral e, em particular, dos organismos e entidades com responsabilidade em matéria de segurança e proteção civil, para a possibilidade de ocorrência de situações meteorológicas adversas. O SAM depende da fiabilidade das previsões meteorológicas e é de extrema importância pois permite adequar as estratégias e procedimentos associados ao planeamento de emergência e atividades de prevenção, informação e socorro.

Com o objetivo de otimizar a utilização do SAM, procedeu-se a uma análise comparativa entre o registo de avisos meteorológicos emitidos diariamente entre 2011 e 2013, as condições meteorológicas e o registo de ocorrências de proteção civil nos mesmos dias. Analisou-se a quantidade e tipologia de ocorrências em dias normais e em dias com Aviso Vermelho e comparou-se o número de dias com aviso emitido com o número de dias com condições reais registadas que justificariam essa emissão.
\end{abstract}

Palavras-chave: Sistema de Avisos Meteorológicos, Ocorrências, Proteção Civil

Introdução

O Sistema de Avisos Meteorológicos (SAM) é assegurado pelo Instituto Português do Mar e da Atmosfera (IPMA), que conta a nível regional com colaboração do Observatório Meteorológico do Funchal (OMF). O IPMA, com base nas previsões meteorológicas efetuadas e num conjunto de critérios pré-definidos, emite avisos com o objetivo de alertar as autoridades de proteção civil e a população em geral para a possível ocorrência de situações meteorológicas extremas. Relativamente à ilha da Madeira, a emissão de avisos é, desde agosto de 2012, feita para três áreas geográficas: 'Costa Norte', 'Costa Sul' e 'Regiões Montanhosas'. A emissão de avisos para Precipitação e Vento, entre outros, segue um critério regional comum, enquanto no caso da Temperatura o critério varia por área geográfica (IPMA, 2014).

Com este trabalho pretende-se contribuir para otimizar a utilização operacional do SAM, comparando os avisos emitidos com os registos meteorológicos nos mesmos dias, e explorando a possibilidade de a situações meteorológicas extremas corresponder um acréscimo de ocorrências de proteção civil.

\section{Metodologia}

Foram recolhidos junto do OMF dados relativos a avisos do SAM emitidos entre 2011 e 2013 para as situações de Vento, Precipitação e Temperatura elevada bem como registos para o mesmo período de 6 estações meteorológicas tomadas por referência: S. Jorge e S. Vicente (Costa 
Norte); Observatório e Ponta do Sol (Costa Sul); Areeiro e Bica da Cana (Regiões Montanhosas). Junto do Comando Regional das Operações e Socorro (CROS) recolheu-se o registo de ocorrências diárias para o mesmo período.

Analisaram-se os dados relativos à ilha da Madeira, que concentra a maioria das ocorrências da RAM, e utilizaram-se as tipologias de Aviso mais relevantes do ponto de vista operacional Precipitação, Vento e Temperatura, e três níveis de Aviso: Amarelo, Laranja e, sobretudo, Vermelho. Analisou-se a evolução da frequência, tipologia, nível e distribuição de avisos emitidos e confrontaram-se os registos de avisos emitidos com as condições meteorológicas registadas nos mesmos dias, nas estações meteorológicas consideradas, nomeadamente nos dias em que efetivamente se atingiram os limiares definidos pelos critérios de emissão de Aviso. Identificados os dias em que registos de pelo menos uma estação correspondem aos critérios para emissão de Aviso Vermelho relativo a Precipitação, Vento ou Temperatura elevada, analisou-se o número de ocorrências do CROS para os mesmos dias e comparou-se com a média diária de cada mês, para o período 2011-2013, desse tipo de ocorrências. Para cada tipo de condição meteorológica selecionou-se um conjunto de tipologias de ocorrência que, com base na experiência operacional se considerou mais pertinente e que habitualmente implica acréscimo na mobilização de meios. A significância da correlação entre a existência ou não de situações meteorológicas equivalentes a critérios de emissão de Aviso Vermelho e o aumento de ocorrências foi estatisticamente validada.

\section{Resultados}

Entre 2011 e 2013 houve um aumento muito significativo dos avisos do SAM emitidos para a RAM, e para a llha da Madeira em particular, onde aumentou de 137 em 2011 para 495 em 2013. 0 número de dias sujeito a aviso também aumentou, ainda que menos significativamente, de 153 dias em 2011 para 215 em 2013.

Considerando os avisos para situações de Vento, Precipitação e Temperatura, a tipologia com maior aumento relativo de número de avisos foi o Vento e a que teve maior aumento relativo de dias com emissão de avisos foi a Temperatura. Em 2011 as situações de Vento coincidiam quer como as que tinham suscitado mais avisos (39\%) quer com mais dias com aviso emitido (38\%). Em 2012 e em 2013 a Precipitação concentrou a maioria dos avisos emitidos (41\% e 39\%). A Temperatura representou em 2012 e 2013 o maior peso no número de dias com aviso emitido (54\% e 50\%).

Considerando os avisos emitidos e o número de dias sujeitos a aviso para as três tipologias referidas, o rácio passou de 0,8 avisos por dia sob aviso em 2011, para 1,3 em 2012 e 2 em 2013, o que significa que a atualização dos avisos se tornou mais frequente. A Precipitação teve o rácio mais alto em 2011 e 2012 (2,1). Em 2013 o rácio da Precipitação foi também elevado $(2,6)$ mas ultrapassado pelo relativo a Vento $(3,1)$.

Entre 2011 e 2013 houve um agravamento no que se refere aos níveis de aviso. Os avisos de nível Amarelo desceram de $91 \%$ para $76 \%$, enquanto os de nível Laranja passaram de $9 \%$ para 19\% e os de nível Vermelho passaram de 0\% em 2011 para 5\% em 2013.

\section{Avisos emitidos e condições meteorológicas registadas}

Foram identificados os dias para os quais houve avisos emitidos relativamente a Vento, Precipitação ou Temperatura elevada na ilha da Madeira, que posteriormente se confrontaram com o registo para esses dias das 6 estações meteorológicas tidas em consideração, de forma a 
verificar se aos avisos correspondeu ou não a concretização de condições meteorológicas equivalentes, de acordo com regras de emissão do IPMA, em pelo menos uma das estações. Consideram-se dois critérios de análise: um que inclui apenas dias em que o aviso emitido e o registo meteorológico foram do mesmo nível (Critério A) e outro que inclui também dias com até 1 nível de diferença (Critério $B$ ).

Em 2011, em 35\% dos dias com aviso emitido para estas tipologias os registos das estações selecionadas registaram, em pelo menos uma delas, valores máximos equivalentes ao aviso emitido (se considerado o Critério B, 68\%). Os avisos relativos a Vento são os que registam maior coincidência (52\%) seguidos de Precipitação (36\%). Considerando o Critério B, a correspondência foi de $68 \%$ para Vento, 50\% para Precipitação e 100\% para Temperatura elevada.

Em 2012 houve 23\% de níveis coincidentes (Critério B, 73\%). Os avisos relativos a Precipitação registaram a maior coincidência (48\%), seguidos de Vento (36\%) e Temperatura (5\%). Considerando o Critério B, a correspondência foi de 78\%, 44\% e 84\% respetivamente. Em 2013 houve uma coincidência entre emissão de aviso e registos meteorológicos em $45 \%$ dos dias (Critério B, 77\%). Os avisos relativos a Vento registaram maior coincidência (58\%), seguidos de Precipitação (43\%) e Temperatura (38\%). Considerando o Critério B, a correspondência foi de $91 \%, 56 \%$ e $80 \%$ respetivamente.

\section{Condições meteorológicas registadas e avisos emitidos}

Contabilizando os dias em que as condições de Vento, Precipitação ou Temperatura máxima justificariam a emissão de um aviso SAM, reportando-se às estações meteorológicas tomadas por referência, contabilizaram-se os dias em que tinha sido emitido um aviso para o mesmo fenómeno.

Em 2011, considerando os dias com registo meteorológico equivalente a aviso, a emissão de avisos do mesmo nível ocorreu em $43 \%$ e $42 \%$ dos dias, relativamente a Precipitação e Vento (Critério B, 57\% e 55\% respetivamente). As situações relativas a Temperatura elevada, pelo contrário, ainda que maioritariamente de nível Amarelo e representando maioria de registos, foram significativamente subestimadas. Em 2012, a coincidência entre dias com condições registadas equivalentes a aviso e dias com aviso emitido do mesmo nível foi de $45 \%$ para a Precipitação e $29 \%$ para Vento (Critério B, 73\% e 35\%). Relativamente a situações de Temperatura elevada, a correspondência foi de $2 \%$ (Critério B, 26\%). Em 2013, a coincidência entre dias com condições registadas equivalentes a aviso e aviso emitido do mesmo nível foi de $43 \%$ para a Precipitação e $37 \%$ para Vento (Critério B, 56\% e 58\%). A percentagem de dias com emissão de avisos do mesmo nível relativamente a Temperatura foi de 9\% (Critério B, 19\%).

\section{Condições meteorológicas adversas e registo de ocorrências}

Considerando as estações meteorológicas utilizadas como referência, identificaram-se os dias em que as condições meteorológicas registadas corresponderam aos critérios de emissão de Aviso Vermelho e contabilizou-se o número de ocorrências registadas no CROS. Este número de ocorrências foi confrontado com a média diária de ocorrências para esse mês, nas mesmas tipologias, no período 2011-2013.

Em 2011 houve 2 dias com registo de condições meteorológicas equivalentes a Aviso Vermelho relativo a Temperatura. No primeiro caso o número de ocorrências foi ligeiramente inferior e no segundo foi ligeiramente superior à média. Em 2012 houve 10 dias nas mesmas condições e 
em 201314 dias, não havendo uma tendência definida - em alguns casos o registo de ocorrências foi superior à média, nos outros inferior.

Relativamente à Precipitação, em 2012 houve 3 dias com registos equivalente a Aviso Vermelho, e nos 3 o aumento de ocorrências foi muito significativo - no mínimo 5 vezes mais. Em 2013 houve 2 dias com condições equivalentes a Aviso Vermelho, ambos com aumento significativo de ocorrências comparativamente à média - 41 e 15 ocorrências para um valor médio diário mensal para essas ocorrências de 3.

Relativamente ao Vento, em 2011 houve um dia com registo equivalente a Aviso Vermelho, sendo que o número de ocorrências (20) foi significativamente superior à média (0.42). Em 2013 houve 3 dias com registos equivalentes a Aviso Vermelho, um em março com 27 ocorrências (média é de 2,54) e dois em dezembro com 15 e 8 ocorrências (média é de 0,43 ).

\section{Conclusão}

Nos últimos anos, o número de avisos emitidos aumentou bastante, com atualizações mais frequentes ao longo do mesmo dia. Este aumento não foi tão expressivo no que se refere a dias com aviso emitido pelo que o rácio aviso/dia aumentou significativamente.

A comparação entre avisos emitidos e condições meteorológicas registadas revela que é significativa a correspondência entre dias com aviso emitido e a concretização de situações meteorológicas adversas registadas em pelo menos uma das estações consideradas. 0 aumento do número de dias com aviso emitido foi acompanhado por um aumento na fiabilidade dos mesmos. Refira-se ainda que as situações relativas a Vento e Precipitação são as que apresentam maior correspondência.

Verificou-se que as situações com maior correspondência entre dias com registos equivalentes a emissão de aviso e a existência de avisos emitidos nesses mesmos dias, referem-se a Vento e Precipitação, frequentemente ultrapassando os $50 \%$, enquanto as situações relativas a Temperatura são mais subestimadas.

Já no que se refere à variação de ocorrências e mobilização de meios pelo CROS, verificou-se que relativamente a situações de Temperatura elevada, e para as tipologias de ocorrência correspondentes, não existe uma tendência definida. Já no que se refere a situações de Vento ou Precipitação intensa, verifica-se que os dias com condições equivalentes a Aviso Vermelho implicaram um número substancialmente mais elevado de ocorrências relacionadas com esses eventos - e a consequente mobilização de meios.

Considera-se pertinente alargar este estudo a um período mais extenso e a um maior número de estações meteorológicas, para uma análise mais detalhada e estatisticamente mais significativa.

\section{Bibliografia}

INE (2002-2013) - Registo de óbitos diários.

IPMA. (junho de 2014). Critérios de Emissão de Avisos. Obtido de IPMA: http: / /www.ipma.pt/pt/enciclopedia/ otempo/sam/index.html?page=criterios. $\mathrm{xml}$

Serviço de Estatística Hospital Dr. Nélio Mendonça (2003-2013) - Registo de admissões no serviço de urgências. Serviço Regional de Proteção Civil, IP - RAM (2011-213) - Ifprotect [base de dados]. Funchal. 